\title{
The efficacy of nonpharmacologic intervention for orthostatic hypotension associated with aging
}

Julia L. Newton, PhD, and James Frith, PhD

Neurology ${ }^{\circledR}$ 2018;91:e652-e656. doi:10.1212/WNL.0000000000005994

\section{Abstract}

\section{Objective}

To determine the efficacy and safety of nonpharmacologic interventions for orthostatic hypotension $(\mathrm{OH})$ secondary to aging.

\section{Methods}

A total of 150 orthostatic challenges were performed in 25 older people (age 60-92 years) to determine cardiovascular responses to bolus water drinking, compression stockings, abdominal compression, and physical countermaneuvers. Primary outcome was response rate as assessed by proportion of participants whose systolic blood pressure (SBP) drop improved by $\geq 10 \mathrm{~mm}$ Hg.

\section{Results}

The response rate to bolus water drinking was $56 \%$ (95\% confidence interval [CI] 36.7-74.2), with standing SBP increasing by $12 \mathrm{~mm} \mathrm{Hg}$ (95\% CI 4-20). Physical countermaneuvers were efficacious in 44\% (95\% CI 25.8-63.3) but had little effect on standing SBP $(+7.5 \mathrm{~mm} \mathrm{Hg}$ [95\% $\mathrm{CI}-1$ to 16]). Abdominal compression was efficacious in 52\% (95\% CI 32.9-70.7) and improved standing SBP $(+10 \mathrm{~mm} \mathrm{Hg}$ [95\% CI 2-18]). Compression stockings were the least efficacious therapy (32\% [95\% CI 16.1-51.4]) and had little effect on standing SBP (+6 mm Hg $[95 \%$ CI $-1,13])$. No intervention improved symptoms during standing. There were no adverse events.

\section{Conclusions}

Bolus water drinking should become the standard first-line nonpharmacologic intervention, whereas compression stockings should be disregarded in this population.

\section{Classification of evidence}

This study provides Class III evidence that for older people with $\mathrm{OH}$, bolus water drinking is superior to other nonpharmacologic interventions in decreasing SBP drop.

\section{Correspondence}

Dr. Frith

james.frith@newcastle.ac.uk

\section{MORE ONLINE}

$\rightarrow$ Class of Evidence
Criteria for rating
therapeutic and diagnostic
studies
NPub.org/coe

$\rightarrow$ Class of Evidence

Criteria for rating

therapeutic and diagnostic studies

From the Institute of Cellular Medicine (J.L.N.), Newcastle University; Falls and Syncope Service (J.L.N., J.F.), Newcastle Upon Tyne Hospitals NHS Foundation Trust; and NIHR Newcastle Biomedical Research Centre (J.F.), Newcastle Upon Tyne Hospitals NHS Trust and Newcastle University, UK.

Go to Neurology.org/N for full disclosures. Funding information and disclosures deemed relevant by the authors, if any, are provided at the end of the article. 


\section{Glossary}

$\mathbf{B P}=$ blood pressure $\mathbf{C I}=$ confidence interval; $\mathbf{O H}=$ orthostatic hypotension .

Orthostatic hypotension $(\mathrm{OH})$ is a disabling condition, resulting from a sustained reduction in blood pressure (BP; $\geq 20 \mathrm{~mm}$ $\mathrm{Hg}$ systolic or $\geq 10 \mathrm{~mm} \mathrm{Hg}$ diastolic) within 3 minutes of standing. ${ }^{1}$ Aging is one of the most common causes of neurogenic $\mathrm{OH}$, affecting $7 \%$ to $30 \%$ of community-dwelling older people. ${ }^{2}$ Clinical guidelines recommend nonpharmacologic therapy as first-line treatment in $\mathrm{OH}$, but older people are typically excluded from research, creating a great deal of clinical uncertainty. ${ }^{3}$ Because the older population is expanding rapidly, we can expect a growing demand for evidence in this area.

\section{Methods}

\section{Population}

All participants were $>60$ years of age and had $\mathrm{OH}$ according to international criteria. ${ }^{1}$ Dysautonomia was confirmed on autonomic function testing and was judged to be secondary to aging (in the absence of other identifiable causes). Exclusions were dysphagia, fluid restriction, and inability to wear compression garments. Participants were recruited via the UK Clinical Trials Gateway and a Falls and Syncope Service in Northeast England.

\section{Setting}

Procedures occurred between 9:30 and 11:30 AM in the Falls and Syncope Service. Participants refrained from caffeine and nicotine and ate a light breakfast only before attending. Medications were withheld for $\geq 12$ hours before attending.

\section{Interventions}

Selection of nonpharmacologic interventions was based on a recent systematic review and recommendations of the $\mathrm{Eu}-$ ropean Federation of Neurological Sciences ${ }^{3,4}$ : bolus water drinking ( $480 \mathrm{~mL}$ tap water consumed within 5 minutes), physical countermaneuvers (standing cross-legged ${ }^{5}$ ), compression stockings (to upper thigh $[23-32 \mathrm{~mm} \mathrm{Hg}]$ ), and abdominal compression (elastic belt).

\section{Procedure}

\section{Visit 1}

To establish a control BP profile, participants rested supine for 10 minutes while undergoing continuous cardiovascular monitoring (Task Force Monitor, CNSystems, Graz, Austria) before standing upright for 3 minutes and noting symptoms. Participants then ingested the water. After 20 minutes, the orthostatic challenge was repeated. ${ }^{6}$

To estimate levels of frailty, dominant handgrip strength was quantified with a hydraulic dynamometer (Jamar, Sammons Preston Inc., Bolingbrook, IL). The Charlson Comorbidity Index score was calculated to illustrate the cohort's comorbidity.

\section{Visit 2}

A control orthostatic BP profile was established with the aforementioned methods. Participants were randomized to the order in which the interventions were administered by selecting a sealed opaque envelope. An orthostatic challenge (supine and standing BP) was repeated for each intervention with a 20-minute washout period between the challenges.

\section{Outcomes}

The primary outcome was response rate to each intervention (proportion of participants whose systolic BP drop improved $\geq 10 \mathrm{~mm} \mathrm{Hg}$ ). The secondary outcomes were nadir standing systolic BP, BP drop, adverse events, and symptoms (Orthostatic Hypotension Questionnaire Symptom Assessment ${ }^{7}$ : participants rate the severity of 6 symptoms [dizziness/lightheadedness, vision, weakness, fatigue, trouble concentrating, head/neck discomfort] from 0 to 10 , from which an average score is derived [maximum severity 10]; the Daily Activity Scale was not evaluated because this is a longer-term measure of symptom impact).

\section{Analysis}

An exact, single-stage, phase 2 study design was used. ${ }^{8}$ The study had $80 \%$ power to demonstrate a $30 \%$ response rate and a $95 \%$ chance of rejecting interventions with response rates $\leq 10 \%$.

The mean and SD are displayed for normally distributed data; median (range) is used for nonparametric data. Response rates with $95 \%$ confidence intervals (CIs) were calculated with the use of exact binomial methods. The paired $t$ test and Wilcoxon signed-rank test were used for statistical comparison of secondary outcomes using 2 -sided $p$ values.

\section{Standard protocol approvals, registrations, and patient consents}

This study was approved by the UK National Research Ethics Service (Newcastle and North Tyneside 2). All participants gave written informed consent. The study was registered prospectively with the UK Clinical Trials Gateway on September 12, 2015 (ISRCTN15084870).

\section{Classification of evidence}

The primary objective was to define the response rate to each therapy. This study provides Class III evidence that for older people with $\mathrm{OH}$, bolus water drinking is superior to other nonpharmacologic interventions in decreasing systolic BP drop.

\section{Data availability}

Anonymized data generated during the current study are available from the corresponding author on reasonable request from individuals affiliated with research or health care institutions. 


\section{Results}

Twenty-five participants were recruited between January and November 2016 (figure 1). Demographic and baseline data are displayed in the table. The median grip strength is slightly lower than UK age-adjusted population norms, suggesting a degree of frailty. ${ }^{9}$ The effect of each intervention on standing systolic BP is shown in figure 2. There were no adverse events. No intervention had a significant impact on the specific symptom of dizziness/lightheadedness (data available from Dryad, table 1, doi.org/10.5061/dryad.h37j22d). Results for the Orthostatic Hypotension Questionnaire Symptom Assessment subscale are provided below.

\section{Bolus water drinking}

The median volume of water consumed was $480 \mathrm{~mL}$ (248-480 $\mathrm{mL}$ ). Fourteen participants responded to bolus water drinking (response rate 56\%, 95\% CI 37\%-74\%). Systolic BP drop was significantly lower after water $(33[19] \mathrm{mm} \mathrm{Hg}, p=0.021)$. There was no effect on diastolic BP drop $(15[12] \mathrm{mm} \mathrm{Hg}, p=$ $0.103)$ or on symptoms $(1[0-8], p=0.923)$.

\section{Physical countermaneuvers}

Eleven participants responded to physical countermaneuvers (response rate 44\%, 95\% CI 26\%-63\%). There was no effect on systolic BP drop (35 [24] mm Hg, $p=0.085$ ) or on symptoms (2.2 [0-6.8], $p=0.117)$. However, diastolic BP drop improved significantly (13 [16] $\mathrm{mm} \mathrm{Hg}, p=0.047)$.

\section{Compression stockings}

Eight participants responded to compression stockings (response rate $32 \%, 95 \% \mathrm{CI} 16 \%-51 \%, p=0.002)$. There was no change in systolic or diastolic BP drop (40 [21] $\mathrm{mm} \mathrm{Hg}, p=0.642$ and18 $[13] \mathrm{mm} \mathrm{Hg}, p=0.815$, respectively) or in symptoms (0.8 [0-7], $p=0.818)$.

Figure 1 Summary of participant screening and enrollment

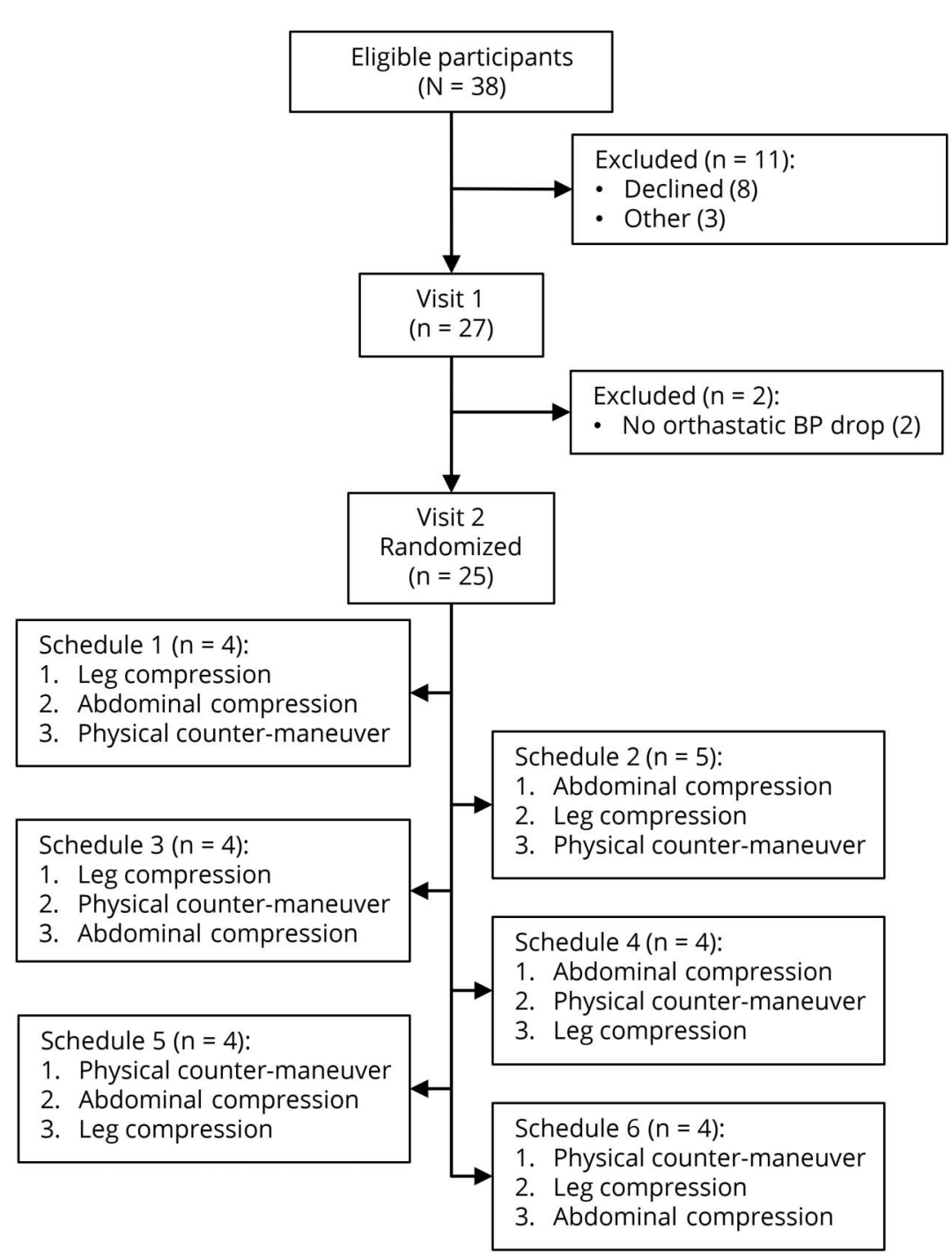

$\mathrm{BP}=$ blood pressure. 


\section{Abdominal compression}

Thirteen participants responded to abdominal compression (response rate 52\%, 95\% CI 33\%-71\%, $p<0.001$ ). Systolic $\mathrm{BP}$ drop reduced significantly (32 [18] $\mathrm{mm} \mathrm{Hg}, p=0.007$ ), but diastolic BP drop did not (15.3 [12] $\mathrm{mm} \mathrm{Hg}, p=0.192)$. There was no change in symptoms $(1.3[0-6.3], p=0.447)$.

\section{Discussion}

This study demonstrates that bolus water drinking is the most efficacious nondrug therapy for aging-associated $\mathrm{OH}$. Abdominal compression and physical countermaneuvers also resulted in reasonable response rates but had variable effects on secondary cardiovascular outcomes. In contrast, full leg length compression resulted in relatively low response rates and had no effect on secondary outcomes. The absence of any effect on symptoms is likely explained by a lack of power to detect small changes in secondary outcomes. The median symptom score was much higher during physical countermaneuvers, possibly due to the cardiovascular effects of physical exertion such as vasodilation or possibly to a reduced standing balance.

Because nonpharmaceutical interventions are recommended as first-line therapy and are preferred by older people, it is essential that we develop a robust evidence base for their use, ${ }^{4}$ particularly in the context of the rapidly expanding older population. ${ }^{10}$ Furthermore, there are special considerations that are relevant to older populations. Older people are more likely to have coexisting problems (e.g., urinary incontinence, limited mobility) that may limit the use of nondrug interventions. Compression garments may also be limited by the difficulties of applying and removing these single-handedly. If clinicians are to recommend therapies when barriers exist, it is important that the value of the intervention is known to aid patient education and ultimately adherence.

This phase II study is relatively small, limiting its external validity. Further evaluation is needed to explore the efficacy of combined therapies and to establish long-term effectiveness.

Table Baseline characteristics

\begin{tabular}{|c|c|c|}
\hline \multicolumn{3}{|l|}{ Demographic } \\
\hline Age, median (range), y & & $74(60-92)$ \\
\hline Male, $n(\%)$ & & $15(60)$ \\
\hline Charlson Comorbidity Index score, median (range) & & $4(3-8)$ \\
\hline Regular medications, median (range) & & $4(0-13)$ \\
\hline Fludrocortisone, $\mathrm{n}$ & & 5 \\
\hline Midodrine, $\mathbf{n}$ & & 3 \\
\hline Dominant hand grip strength, median (range), kg & & $25(2-54)$ \\
\hline Demographic & Visit 1 & Visit 2 \\
\hline \multicolumn{3}{|l|}{ Control supine $B P$, mean (SD), mm Hg } \\
\hline Systolic & $128(21)$ & $126(19)$ \\
\hline Diastolic & $75(13)$ & $77(12)$ \\
\hline \multicolumn{3}{|l|}{ Control standing BP nadir, mean (SD), mm Hg } \\
\hline Systolic & $87(26)$ & $84(25)$ \\
\hline Diastolic & $57(13)$ & $59(16)$ \\
\hline \multicolumn{3}{|l|}{ Control orthostatic BP drop, mean (SD), mm Hg } \\
\hline Systolic & $41(22)$ & $41(20)$ \\
\hline Diastolic & $19(13)$ & $18(13)$ \\
\hline \multicolumn{3}{|c|}{ Control orthostatic symptoms, OHSA score, median (range) } \\
\hline Composite symptom score & $1(0-8.5)$ & $1.2(0-6)$ \\
\hline Dizziness & $2(0-9)$ & $4(0-9)$ \\
\hline
\end{tabular}

Abbreviations: BP = blood pressure; OHSA = Orthostatic Hypotension Questionnaire Symptom Assessment subscale.

Control indicates values derived from baseline postural BP measurement before intervention. Maximum OHSA score is 10 ; maximum dizziness score is 10. 


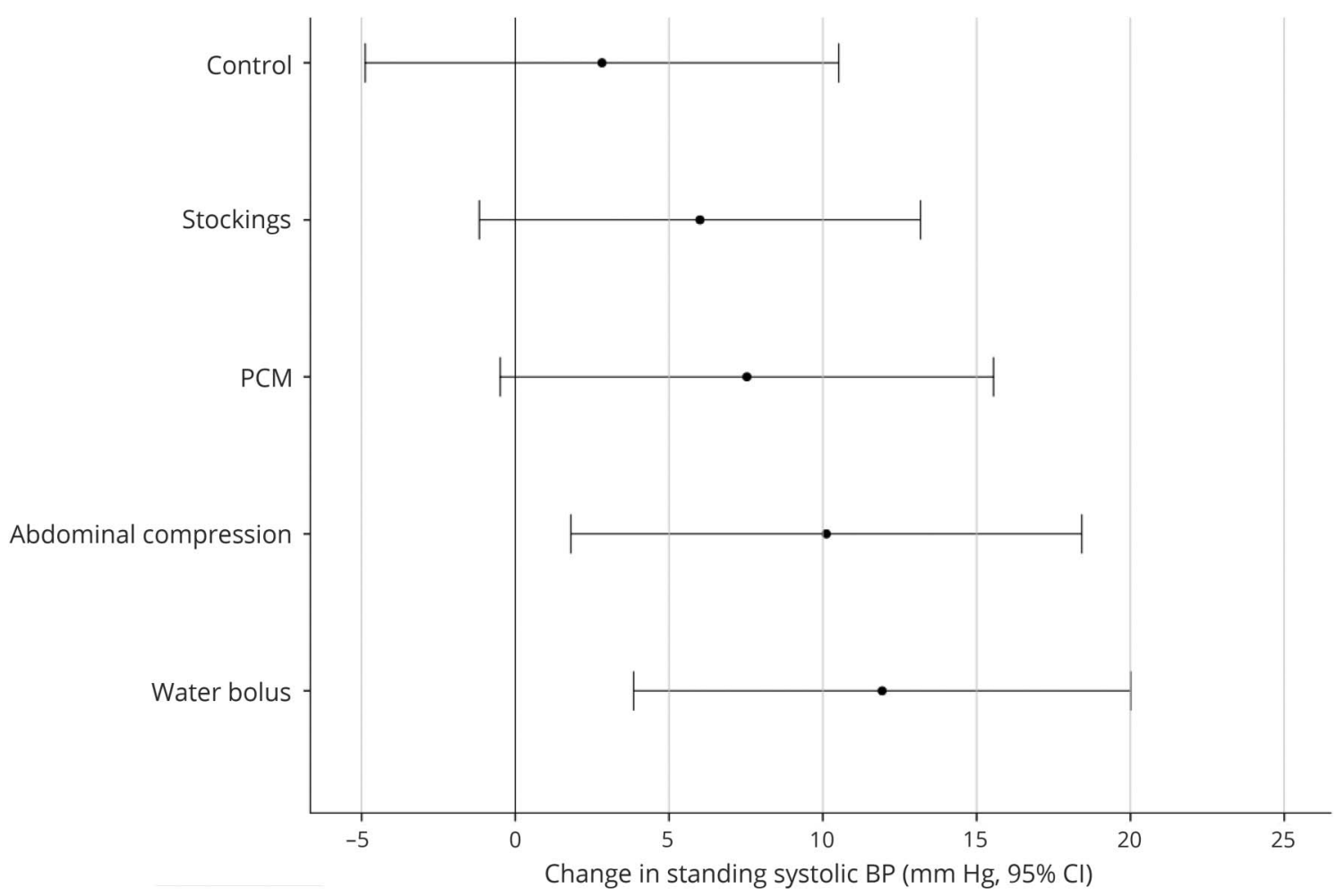

Change in standing systolic blood pressure (BP) with each intervention compared to no intervention. Control refers to the difference between the baseline postural $\mathrm{BP}$ assessments on visits 1 and 2 . $\mathrm{Cl}=$ confidence interval; $\mathrm{PCM}=$ physical countermaneuver.

It is important to note that in each case, the control orthostatic BP was performed first, closer in time to any preceding meal. This could have exerted greater postprandial hypotensive effects on the control BP compared to the interventions, exaggerating the beneficial effects of the interventions.

Bolus water drinking should become the standard first-line nonpharmacologic intervention, whereas compression stockings should be disregarded in this population.

\section{Author contributions}

J.L.N.: study concept, data interpretation, manuscript preparation. J.F.: study concept and design, data collection, analysis and interpretation, statistical analysis, and manuscript preparation.

\section{Study funding}

No targeted funding reported.

\section{Disclosure}

Dr. Newton: has received research funding from UK National Institute for Health Research Efficacy and Mechanism Evaluation, Arthritis Research UK, ME Research UK and Action for ME. Dr. Frith: This report is independent research arising from a Clinician Scientist Award (CS-2014-14-002) supported by the UK National Institute for Health Research. The views expressed in this publication are those of the authors and not necessarily those of the UK NHS, the National Institute for Health Research, or the Department of Health. Dr. Frith has also received research funding from The Dowager Countess Eleanor Peel Trust. Go to Neurology.org/N for full disclosures.

Received November 23, 2017. Accepted in final form May 11, 2018.

\section{References}

1. Freeman R, Wieling W, Axelrod FB, et al. Consensus statement on the definition of orthostatic hypotension, neurally mediated syncope and the postural tachycardia syndrome. Clin Auton Res 2011;21:69-72.

2. Low PA. Prevalence of orthostatic hypotension. Clin Auton Res 2008;18:8-13.

3. Mills PB, Fung CK, Travlos A, Krassioukov A. Nonpharmacologic management of orthostatic hypotension: a systematic review. Arch Phys Med Rehabil 2015;96: 366-375 e366.

4. Lahrmann H, Cortelli P, Hilz M, Mathias CJ, Struhal W, Tassinari M. EFNS guidelines on the diagnosis and management of orthostatic hypotension. Eur J Neurol 2006;13:930-936

5. Wieling W, van Dijk N, Thijs RD, de Lange FJ, Krediet CT, Halliwill JR. Physical countermeasures to increase orthostatic tolerance. J Intern Med 2015;277:69-82.

6. Jordan J, Shannon JR, Black BK, et al. The pressor response to water drinking in humans: a sympathetic reflex? Circulation 2000;101:504-509.

7. Kaufmann H, Malamut R, Norcliffe-Kaufmann L, Rosa K, Freeman R. The Orthostatic Hypotension Questionnaire (OHQ): validation of a novel symptom assessment scale. Clin Auton Res 2012;22:79-90.

8. A'Hern RP. Sample size tables for exact single-stage phase II designs. Stat Med 2001, 20:859-866.

9. Dodds RM, Syddall HE, Cooper R, et al. Grip strength across the life course: normative data from twelve British studies. PLoS One 2014;9:e113637.

10. Frith J, Elliott CS, Bashir A, Newton J. Public and patient research priorities for orthostatic hypotension. Age Ageing 2014;43:865-868. 


\section{Neurology}

\section{The efficacy of nonpharmacologic intervention for orthostatic hypotension associated with aging}

Julia L. Newton and James Frith

Neurology 2018;91;e652-e656 Published Online before print July 13, 2018

DOI 10.1212/WNL.0000000000005994

\section{This information is current as of July 13, 2018}

\section{Updated Information \&} Services

References

Citations

Subspecialty Collections

Permissions \& Licensing

Reprints including high resolution figures, can be found at: http://n.neurology.org/content/91/7/e652.full

This article cites 10 articles, 1 of which you can access for free at: http://n.neurology.org/content/91/7/e652.full\#ref-list-1

This article has been cited by 3 HighWire-hosted articles: http://n.neurology.org/content/91/7/e652.full\#\#otherarticles

This article, along with others on similar topics, appears in the following collection(s):

\section{Autonomic diseases}

http://n.neurology.org/cgi/collection/autonomic_diseases

Syncope

http://n.neurology.org/cgi/collection/syncope

Information about reproducing this article in parts (figures,tables) or in its entirety can be found online at:

http://www.neurology.org/about/about_the_journal\#permissions

Information about ordering reprints can be found online:

http://n.neurology.org/subscribers/advertise

Neurology ${ }^{\circledR}$ is the official journal of the American Academy of Neurology. Published continuously since 1951 , it is now a weekly with 48 issues per year. Copyright Copyright (C) 2018 The Author(s). Published by Wolters Kluwer Health, Inc. on behalf of the American Academy of Neurology.. All rights reserved. Print ISSN: 0028-3878. Online ISSN: 1526-632X.

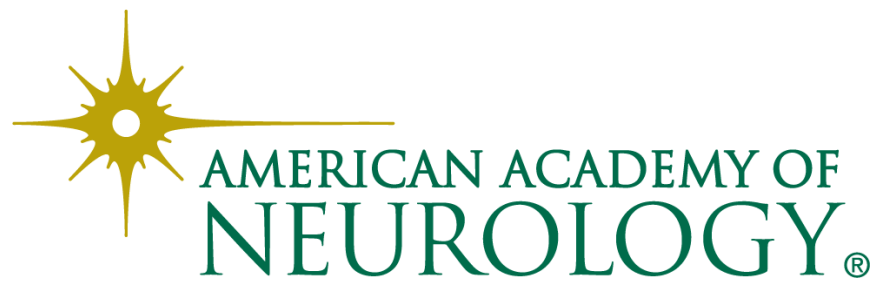

